\title{
DESIGN AND DEVELOPMENT OF NOVEL PATCH ANTENNA FOR 2.4GHz WLAN APPLICATIONS
}

\author{
G. Geetharamani ${ }^{1}$ and T. Aathmanesan ${ }^{2}$ \\ ${ }^{1}$ Department of Mathematics, Anna University, Chennai, India \\ ${ }^{2}$ Department of Information and Communication Engineering, Anna University, Chennai, India
}

\begin{abstract}
Antenna plays major role in increasing the communication standards to meet the requirements of modern technology driven industries and personal data services. In this paper a novel patch antenna for $2.4 \mathrm{GHz}$ WLAN applications presented. The proposed antenna has novel shaped radiator along with modified ground plane with $24 \times 25 \mathrm{~mm}^{2}$ overall dimension. The proposed antenna developed on the FR4 substrate with dielectric permittivity of 4.4 and height of the substrate is $1.6 \mathrm{~mm}$ and loss tangent of 0.002 to achieve lower return loss possible. The proposed antenna simulated in an integral based solver simulation software called CST Microwave studio v2019 and obtained results such as VSWR 1.31, return loss $-17.29 d B$ with bandwidth of $130 \mathrm{MHz}$, gain of 3.93dBi and efficiency of $82.96 \%$. This antenna suitable for WLAN applications which uses $2.4 \mathrm{GHz}$ resonant frequency.
\end{abstract}

Keywords:

WLAN, Patch Antenna, Modified Ground

\section{INTRODUCTION}

The expansion of wireless communication helps our daily high-speed data requirements and improves the capacity of professional networking. The data driven industries needs more powerful connections for sustaining the business growth. To meet all these requirements developing new antenna technology is unavoidable in improving the overall efficiency of wireless communication. Wireless Local Area Networks (WLANs) is capable of providing larger range or coverage, with high throughput while providing high power consumption at the lowest cost. The IEEE 802.11 specification was approved in July 1997, since then $2.4 \mathrm{GHz}$ is widely driving major WLAN communication. Therefore, this paper focuses on the design of two element series-fed two dipole antenna for providing $2.4 \mathrm{GHz}$ base station applications [4].

The design of single element series-fed two dipole antenna has already been developed and discussed in [4] which performed well. Still to increase its usefulness and coverage area the fundamental design is used for developing two element antenna systems keeping the mutual coupling under control along with the other parameters for developing a new two element series-fed two dipole antenna. The software used in this work is CST Microwave studio v2018. CST microwave studio is an electromagnetic field simulation software which is based on finite integration technique and for analysis of patch antennas time domain solver is used. This CST microwave studio is selected based on its user interface, which is very simple and has the capability of simulating complex structures.

The need for developing new antennas for increasing communication standards is important for expanding the uses of wireless applications. IEEE specifies IEEE $802.11 \mathrm{~b}$ is a data rate extension of the initial 802.11 standard for wireless local area network (WLAN) operation in the $2.4 \mathrm{GHz}$ band. There are several antennas available for $2.4 \mathrm{GHz} \mathrm{Wi}-\mathrm{Fi}$ applications since the size of the antennas [4]-[6] were larger and intended for use in larger coverage areas. There is a need for smaller antennas with the extended performance required was identified as a problem statement for this research paper from the literature review given in section 2 .

Therefore, this paper focuses on developing a novel antenna with the improved performances for the use of WLAN applications. The software used in this work is CST Microwave studio v2019. CST microwave studio is an electromagnetic field simulation software which is based on finite integration technique and for analysis of patch antennas time domain solver used. This CST microwave studio selected based on its user interface, which is very simple and has the capability of simulating complex structures. The proposed antenna has a novel radiating patch in the top and modified ground plane at the bottom for resonating in $2.4 \mathrm{GHz}$ frequency.

The organization of this paper includes the introduction section as first part followed by the literature review and design methodology followed in the progress of the proposed antenna and the next section consists of results and discussion section and finally conclusion and future works completes the paper.

\section{LITERATURE REVIEW}

The literature review consists of the basics of micro patch antennas [1-3], in [4] Series fed two dipole antennas for WLAN base station applications for small coverage area with $105 \times 80 \mathrm{~mm}^{2}$ with gain of $6.19 \mathrm{~dB}$ discussed. In [5] two element series-fed two dipole antenna for medium coverage area with $105 \times 160 \mathrm{~mm}^{2}$ with gain of $8.68 \mathrm{~dB}$ gain discussed. In [6], four element series-fed two dipole antenna array for larger coverage area with $160 \times 105 \times 160 \mathrm{~mm}^{3}$ with gain of $11.9 \mathrm{~dB}$ discussed. In [7], a compact patch antenna for $2.4 \mathrm{GHz}$ presented. In [8] Dual layer rectangular microstrip patch antenna with $\mathrm{H}$-slot for $2.4 \mathrm{GHz}$ range applications in which split ring resonator used for the gain improvement. In [9] Design of slotted $\mathrm{H}$-shaped patch antenna for $2.4 \mathrm{GHz}$ WLAN applications discussed in which the slot contributes to the improved the overall performance of the antenna. In [10] Small size circularly polarized patch antenna for 2.4GHz WLAN applications presented which uses meandered feeding structure in the square slot for the design of the antenna. In [11] Very-low-profile, 2.4/5GHzWLAN monopole antenna for large screen-to-body-ratio notebook computers discussed. In [12] Compact dual-band antenna with slotted ground for implantable applications which uses open ended slots in the ground plane for achieving the improved bandwidth. In [13] Compact CPW-fed 
planar monopole antenna with distinct triple bands for WiFi/WiMAX applications discussed which uses three different types of structures two I-shaped notched slots, an open-ended Ushaped slot and two symmetrical meander microstrip-lines for obtaining the required bands for operation. In [14] Compact fourelement SRR-loaded dual-band MIMO antenna for WLAN/WiMAX/WiFi/4G-LTE and 5G applications discussed which uses SRR-loaded ILA for the better performance. In [15] Analysis of the microstrip-grid array antenna and proposal of a new high-gain, low-complexity and planar long-range $\mathrm{WiFi}$ antenna with $292 \times 210 \times 9.9 \mathrm{~mm} 3$ dimension for outdoor applications discussed. Different antennas available in literature for huge coverage area with larger size in the literature. The need for small antennas for shorter coverage area is still exists therefore in this paper a novel patch antenna presented for operating $2.4 \mathrm{GHz}$ resonant frequency WLAN applications.

\section{ANTENNA DESIGN}

The proposed antenna shown in Fig.1. The overall dimension of the proposed antenna consists of length $a$. which is $25 \mathrm{~mm}$ and width $b$ is $24 \mathrm{~mm}$ dimension. The Fig.1.(a) shows the front view of the proposed antenna which consists of novel radiating structure which obtained from modifying the normal rectangular shaped patch and the slot introduced in the center of the patch is responsible for the generation of the resonating frequency $2.4 \mathrm{GHz}$.

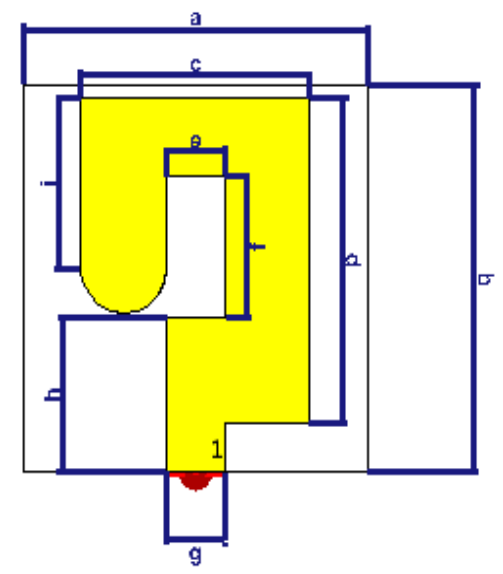

(a) Front View

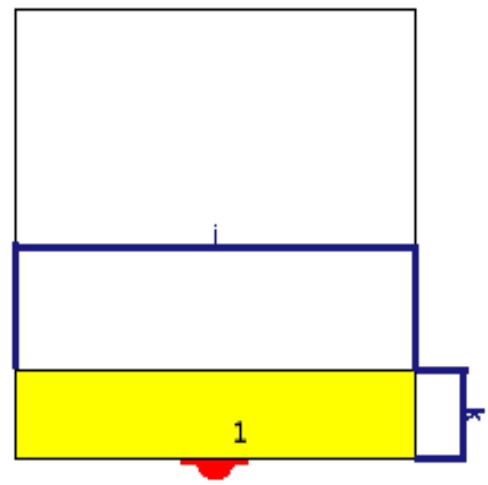

(b) Back View

Fig.1. Proposed Antenna
The Fig.1(b) shows the back view of the proposed antenna which consists of modified ground structure which is responsible for the impedance matching. The dimensions of the antenna finalized after several iterations to meet the requirements of the WLAN standards. The proposed antenna developed on FR4 Substrate with permittivity of 4.3 and thickness $1.6 \mathrm{~mm}$. The patch designed in copper material having electrical conductivity of $5.8 \mathrm{e}^{7}$ with a thickness of $0.035 \mathrm{~mm}$.

The variation of return loss observed during the simulation process for finalizing the modified ground plane dimension. From the variation of return loss plot it is observed that the resonant frequency $2.4 \mathrm{GHz}$ is obtained at parameter $k$ at $5 \mathrm{~mm}$. The Table. 1 shows the parameters used in the dimensions of the proposed antenna.

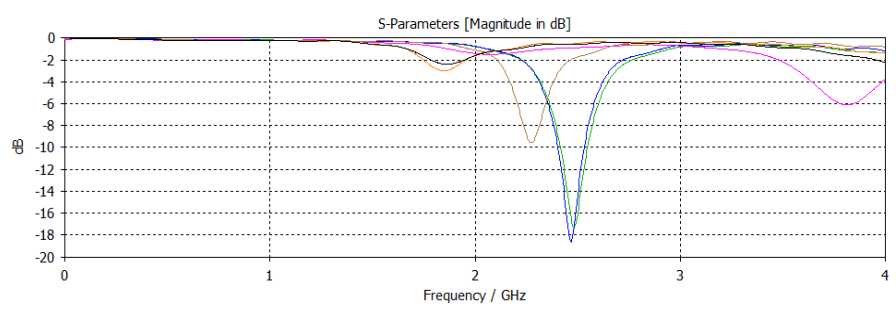

Fig.2. Variation of Return loss

Table.1. Dimension

\begin{tabular}{|c|c|}
\hline Parameter & Dimension $(\mathbf{m m})$ \\
\hline A & 24 \\
\hline B & 25 \\
\hline C & 16 \\
\hline D & 21 \\
\hline E & 4 \\
\hline F & 9.21 \\
\hline G & 4 \\
\hline H & 10 \\
\hline I & 11 \\
\hline J & 24 \\
\hline K & 5 \\
\hline
\end{tabular}

\section{RESULTS AND DISCUSSION}

In this section the results and discussion presented. The design and simulation done using CST microwave studio v2019 and its results such as return loss, VSWR, farfield radiation, surface current, gain and efficiency discussed below.

\subsection{RETURN LOSS}

Return loss is the loss of power in the signal returned/reflected by a discontinuity in a transmission line. The minimum return loss at $2.4 \mathrm{GHz}$ is $-17.29 \mathrm{~dB}$ for the proposed antenna shown in Fig.3. The $-10 \mathrm{~dB}$ Bandwidth obtained at $2.4 \mathrm{GHz}$ is $130 \mathrm{MHz}$.

\subsection{VSWR}

VSWR stands for Voltage Standing Wave Ratio, and is also referred to as Standing Wave Ratio (SWR). VSWR is a function 
of the reflection coefficient, which describes the power reflected from the antenna. The minimum VSWR (Voltage Standing Wave Ratio) obtained at $2.4 \mathrm{GHz}$ is 1.31 for the proposed antenna which given in Fig.4. The VSWR value must be from 1 to 1.5 for the perfect antenna and the proposed design achieves the value of 1.31 is closer to the perfect value.

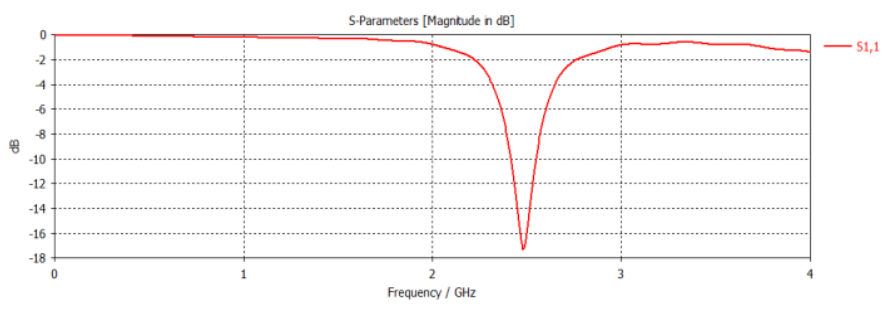

Fig.3. Return loss

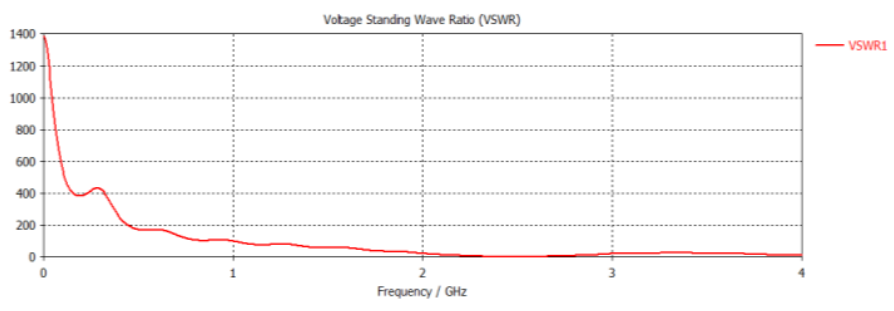

Fig.4. VSWR

\subsection{SURFACE CURRENT DISTRIBUTION}

Surface current distribution is a useful tool for analyzing the performance of the antenna design. The Fig. 5 shows the surface current distribution obtained at $2.4 \mathrm{GHz}$ resonant frequency. From the Fig.4, at resonant frequency the maximum current distribution observed at the novel slot region in the radiating patch designed on the proposed antenna. The current flow starts from the feeding point equally distributed over the radiating patch and the modified ground region.

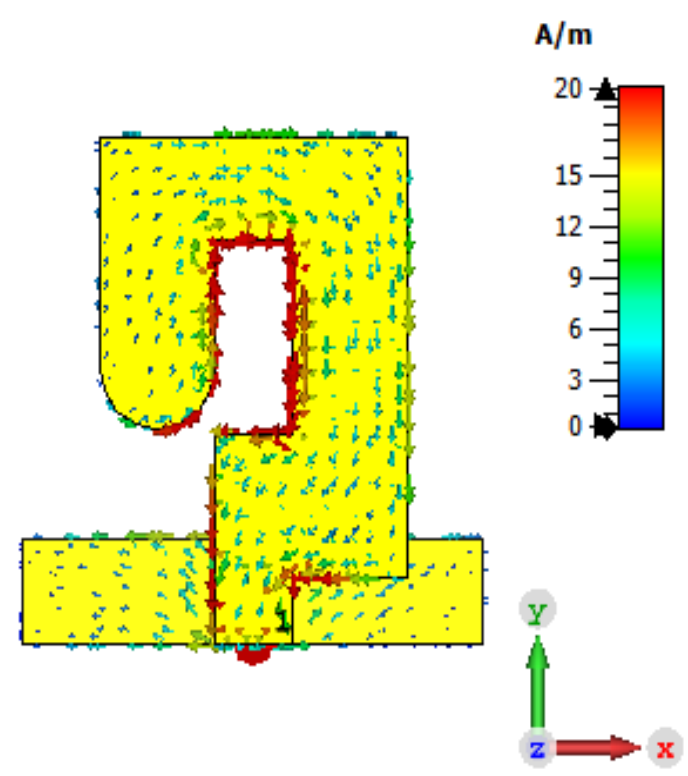

Fig.5. Surface Current Distribution

\subsection{FARFIELD ANALYSIS}
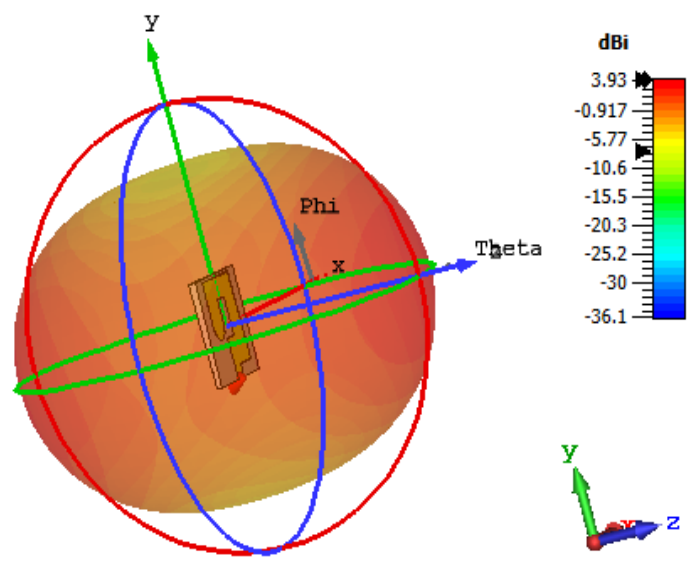

Fig.6. Farfield at $2.4 \mathrm{GHz}$

The 3D pattern in Fig.6 shows the distribution of the power radiated by an antenna as a function of the direction away from the antenna. The maximum gain obtained at $2.4 \mathrm{GHz}$ is $3.93 \mathrm{dBi}$.

\subsection{EFFICIENCY}

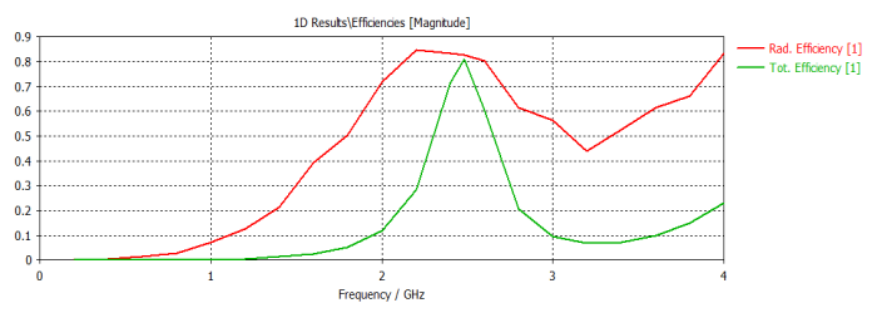

Fig.7. Efficiency

The maximum radiation efficiency obtained at $2.4 \mathrm{GHz}$ $82.69 \%$ and the total efficiency from 0 to $4 \mathrm{GHz}$ frequency range is $81.14 \%$ for the proposed antenna.

\subsection{ELEVATION AND AZIMUTH PATTERN}

The Fig. 8 shows the elevation pattern of radiation by the proposed antenna is like the dipole radiation pattern and the Fig.9 shows the Azimuth pattern of radiation which follows the omnidirectional pattern which clearly shows that the proposed antenna has better radiation characteristics to support $2.4 \mathrm{GHz}$ wireless communication applications. The Table. 2 summarizes the overall results obtained by the proposed antenna.

Table.2. Overall Results

\begin{tabular}{|c|c|}
\hline Parameter & Value \\
\hline Frequency & $2.4 \mathrm{GHz}$ \\
\hline Return Loss & $-17.29 \mathrm{~dB}$ \\
\hline VSWR & 1.31 \\
\hline Gain & $3.93 \mathrm{dBi}$ \\
\hline Efficiency & $82.69 \%$ \\
\hline Bandwidth & $130 \mathrm{MHz}$ \\
\hline
\end{tabular}




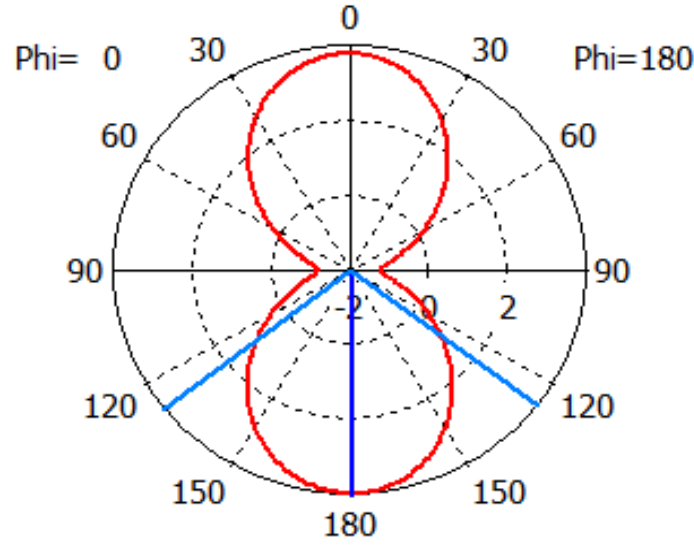

Theta / Degree vs. dBi

Fig.8. Elevation Pattern

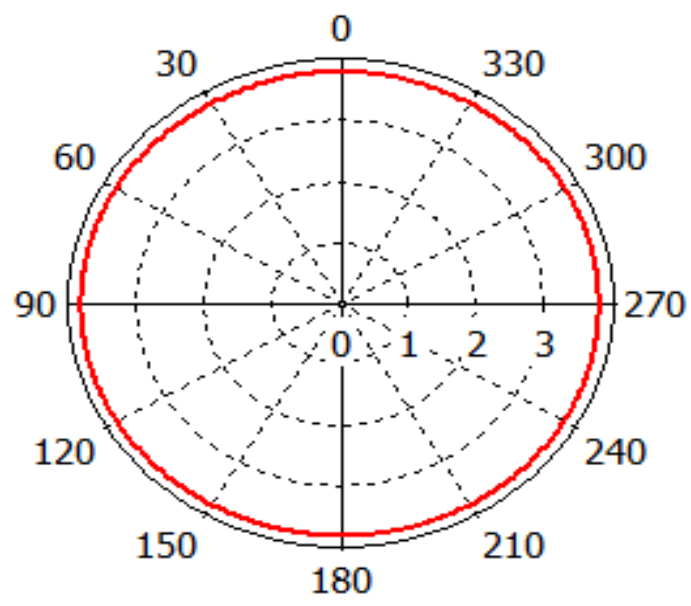

Phi / Degree vs. dBi

Fig.9. Azimuth Pattern

\section{CONCLUSION AND FUTURE WORKS}

A novel patch antenna for $2.4 \mathrm{GHz}$ WLAN applications discussed in this paper. The proposed antenna simulated in CST Microwave Studio V2019 and its results such as return loss of $17.29 \mathrm{~dB}$, VSWR 1.31, gain $3.93 \mathrm{dBi}$ and bandwidth $130 \mathrm{MHz}$ are following the IEEE 802.11b guidelines for operating WLAN applications in ISM Band frequency. The proposed antenna has smaller dimensions when compared to the previous works listed in literature and its performance parameters were suitable for WLAN applications where the coverage area is low. The future work will be focusing on improvement of its gain and other performance parameters.

\section{REFERENCES}

[1] C.A. Balanis, "Antenna Theory: Analysis and Design", $2^{\text {nd }}$ Edition, Wiley, 1997.

[2] D.M. Pozar and D.H. Schaubert, "Microstrip Antennas: The Analysis and Design of Microstrip Antennas and Arrays", IEEE Press, 1995.

[3] Yi Huang and Kevin Boyle, "Antennas from Theory to Practice", Wiley, 2008.

[4] T. Aathmanesan and G. Geetharamani, "Design and Development of Series Fed Two Dipole Antenna for WLAN Base Station Applications", ICTACT Journal on Microelectronics, Vol. 4, No. 1, pp. 515-518, 2018.

[5] V. Kumar, "Compact Patch Antenna for 2.4GHz", Proceedings of $4^{\text {th }}$ International Conference on Electronics and Communication Systems, pp. 78-82, 2017.

[6] H. Nornikman, F. Malek, N. Saudin, N.A. Zainuddin, M.M. Shukor, M.Z. Aziz and M.A. Othman, "Dual Layer Rectangular Microstrip Patch Antenna with $\mathrm{H}$-slot for $2.4 \mathrm{GHz}$ Range Applications", Proceedings of $3^{\text {rd }}$ International Conference on Instrumentation, Communications, Information Technology and Biomedical Engineering, pp. 1-6, 2013.

[7] E. Aravindraj and K. Ayyappan, "Design of Slotted HShaped Patch Antenna for 2.4GHz WLAN Applications", Proceedings of International Conference on Computer Communication and Informatics, pp. 23-29, 2017.

[8] J.W. Yang, T.Y. Tsai, C.C. Chan and C.Y.D. Sim, "Small Size Circularly Polarized Patch Antenna for 2.4GHz WLAN Applications", Proceedings of $5^{\text {th }}$ IEEE Asia-Pacific Conference on Antennas and Propagation, pp. 26-29, 2016.

[9] S.W. Su, "Very-Low-Profile, 2.4/5 GHzWLAN Monopole Antenna for Large Screen-to-Body-Ratio Notebook Computers", Microwave and Optical Technology Letters, Vol. 60, No. 5, pp. 1313-1318, 2018.

[10] L. Luo, B. Hu, J. Wu, T. Yan and L.J. Xu, "Compact DualBand Antenna with Slotted Ground for Implantable Applications", Microwave and Optical Technology Letters, Vol. 62, No. 1, pp. 1-6, 2019.

[11] P. Wang, G.J. Wen, Y.J. Huang and Y.H. Sun, "Compact CPW-Fed Planar Monopole Antenna with Distinct Triple Bands for WiFi/WiMAX Applications", Electronics Letters, Vol. 48, No. 7, pp. 357-366, 2012.

[12] D. Sarkar and K.V. Srivastava, "Compact Four-Element SRR-Loaded Dual-Band MIMO Antenna for WLAN/WiMAX/WiFi/4G-LTE and 5G Applications", Electronics Letters, Vol. 53, No. 25, pp. 1623-1624, 2017.

[13] S.D. Assimonis, T. Samaras and V. Fusco, "Analysis of the Microstrip-Grid Array Antenna and Proposal of a New High-Gain, low-Complexity and Planar Long-Range WiFi Antenna", IET Microwaves, Antennas and Propagation, Vol. 12, No. 3, pp. 332-338, 2018. 